Published in Journal of the Philosophy of Sport, vol. 35, no. 1 (2008): 1-16

10.1080/00948705.2008.9714724

\title{
Remote Sport: Risk and Self-Knowledge in Wilder Spaces Leslie A. Howe
}

\begin{abstract}
Previous discussions on the value of sport in remote locations have concentrated on 1) environmental and process concerns, with the rejection of competition and goal-directed or use oriented activity, or 2) the value of risk and dangerous sport for self-affirmation. It is argued that the value of risk in remote sport is in self-knowledge rather than self-affirmation and that risk in remote sport, while enhancing certain kinds of experience, is not necessary. The value of remote sport is in offering the opportunity for experience that enhances the participants' knowledge both of self and of the environment with which they interact.
\end{abstract}

What benefit is to be obtained from doing sports in remote, wild, or natural environments rather than indoors or outdoors on fields or other playing surfaces deliberately constructed for the purpose and located within more or less urban environments? Why climb a frozen cliff-face rather than an indoor climbing-wall; why hike high windy hills, bug-infested forests, and muddy river valleys rather than pounding a treadmill, a familiar roadway, or a track oval? Why paddle a glacial stream or ocean fjord rather than flatwater lanes? Why ski or snowboard the backcountry rather than a resort with groomed slopes, lifts, and a spa? The question I pose here is not simply "which would you prefer to do?" though it may prove that personal taste will indeed bear heavily on any given individual's answer, but what experiential or ontological gain is there to the sportsperson in taking his or her activity to "the great outdoors"?

Because I assume that aesthetic preferences are insufficient to outweigh moral considerations, and because outdoor and what I shall refer to as "remote sport" frequently raise such concerns, it is important for us to find an answer to this question that goes beyond this simple preference. What I shall argue in this paper is that engaging in remote sport as I shall define it can advance our knowledge of self in appreciable ways. All sport has the potential to develop self-understanding and personal growth by offering various kinds of test, but sport carried out in the remote and wilder places of the earth elevates this benefit because it commonly demands a higher than usual awareness of and response to risk, as well as presenting participants with a practical revelation of their relative significance (or lack thereof) in the natural environment. It can teach us not only about ourselves as human individuals, but also as humans placed in a wider world than the purely human. My claim is not therefore that remote sport is better than conventional sport as such, but that it does have some special benefits to offer.

In this paper, I use the umbrella term "remote sport" to refer to those sports a defining feature of which is their direct engagement with some feature of the natural as opposed to the strictly social human environment, and as the opposite of "urban sport". This distinction requires some further explanation. Remote sport isn't simply sport out of doors. There are a great many sports performed out of doors, that would nevertheless count as urban sport, such 
as football, rowing, and downhill skiing on groomed and fully serviced hills. These ordinarily take place within an urban environment, relying on a critical concentration of population and on a civic infrastructure in the form of buildings, services (roads, plumbing, electricity, etc.) and facilitated client access. ${ }^{1}$

I am also assuming that remote sports tend to be "self-propelled" activities. Insofar as remote sport is concerned with achieving an authentic experience, whether of the natural world, one's own kinaesthetic expression, or (preferably) of both these together, this experience and its authenticity are likely to be enhanced by one's reliance on one's own physical effort. If what one is trying to do is to test oneself against some natural feature, to find one's personal limits, to experience one's connection with it, or merely to appreciate the profound and indifferent beauty of the wilder places of the earth, it make sense to do so oneself, as an organic human being rather than through the medium of a motorised vehicle. It makes sense to endeavour to reduce so far as possible or at least practicable the artefacts intervening between self and wild. Of course, there are vital limits. All remote sports make some use, and often high use, of technology and only fools try to climb mountains without any relevant clothing or equipment. $^{2}$ Death is, of course, a potentially authentic experience but an unproductive one.

Remote sports aren't necessarily remote in terms of distance, either. "Remoteness", as I use the term here, refers to a complex characteristic, a combination of distance measured in kilometres, avoidance of certain kinds of sport infrastructure, and, very often, distance from rescue and/or difficulty of escape. Thus, risk is often though not necessarily present in a different way than it is in urban sports (some of which may well carry a higher absolute likelihood of serious injury). It is perhaps also worth noting that "remoteness" is often a relative and perhaps even ethnocentric term: a tricky white water river is not so remote to the person who makes a living on its banks as it is to the one who travels eight or ten time zones to shoot its rapids.

Remote sports participants are frequently, but not necessarily, under a greater than normal risk of serious injury and death, and often without ready recourse to medical assistance or rescue. Thus remote sport is also "remote" in the sense that the participants are more or less on their own. Rescue or assistance is, for the most part, either up to the participants themselves or only available at significant expense and difficulty. ${ }^{3}$ Breaking a leg on a soccer

${ }^{1}$ It is true that many remote sports also need funding, equipment, sometimes complex and expensive means of access to the areas in which they are performed and, not infrequently, make use of an extended community of participants and informally regulatory structure (as in clubs, associations, and grading systems for difficulty). However, this is not necessarily the case. And, of course, all human endeavours, in remote or urban sport, and in ordinary life, even in the bush, do require an at least minimal and often considerable background of social credit (language, education, technology, etc.), but I think it reasonable to take this as read.

${ }^{2}$ Which isn't to say that people don't try. Witness the frequent "assaults" on Snowdon by tourists in jeans and t-shirts, and the sad story of Chris McCandless (8).

${ }^{3}$ Of course, in some cases there are extensive (and expensive) rescue systems in place that the remote sportsperson can rely on. The existence of such systems is sometimes controversial, not least because they are viewed by some as obviating the need for responsible 
pitch and doing so on a mountain side have very different consequences. Moreover, in the latter situation, it may make relatively little difference if one does so in the Karakoram, northern Norway, or Jasper. Thus, "remoteness" may have more to do with distance from external aid than it does simple kilometrage.

What seems most to define the difference between urban and remote sport is that while the sport itself remains an artificial human construct, its "field of play" does not. That is, mainstream urban sport, whether "organised" or not, explicitly constructs its conditions and arena of play: whether its parametres are defined spatially, temporally, in terms of participants (who, how many, are there teams, what do each of the participants do, etc.), or equipment (bats, balls, pucks, oars, wheels, each of such-and-such size, composition, etc.). Such sports are generally strictly defined in at least one and usually several dimensions. Moreover, and crucially, these definitional boundaries commonly cut across and contravene natural boundaries, either exaggerating or ignoring them. As Krein points out ${ }^{4}$, a playing-field rolls over or rebuilds nature, making it colder, smoother, squarer, rounder, springier, etc. A golf-course or a ski-hill reconstructs and artificialises nature in a less obvious way than a football field or ice-rink, but just as thoroughly, because in all these cases the world is made to fit the sport rather than the reverse. ${ }^{5}$

Urban sport rationalises the structure of the world in ways that remote sport, by and large, though not absolutely, does not. Because urban sport is designed to determine the fastest, strongest, most skilled, etc., of its participating competitors, to do so in a meaningful way it must ensure that the competitive conditions are fair, which means uniform for all participants and in all iterations of a given sport. Thus there are weight, age, sex, and experience classes, rules concerning minimum and maximum dimensions of equipment used, and officials to ensure that all competitors abide by these rules. If these provisions are violated, such sports fail to accomplish their ends. Such uniformity is precisely what one attempts to avoid in remote sport in favour of the richness and relative unpredictability of natural variation. In this respect, it is easy for some to see modern sport as over-civilised, the product of bureaucrats, kinesiology labs, and marketting.

Urban sport builds its own field of play as definitive of itself and as a test of the human

self-reliance and to some degree negate or dilute exactly the "remoteness" to which I here refer. See Simon (21). Also cf. Krakauer (10: p. 176): "During my thirty-four year tenure as a climber, I'd found that the most rewarding aspects of mountaineering derive from the sport's emphasis on self-reliance, on making critical decisions and dealing with the consequences, on personal responsibility."

${ }^{4}$ Krein (11). Much of this discussion and that in the next paragraph is suggested by Krein's article. The conclusions I draw from it, however, are on my own responsibility.

${ }^{5}$ There are a few sports that hover between these categories: cross country running and skiing, yachting, etc. I would be inclined to say that they remain "urban" if other defining constraints are used, time, for example. A cross country runner follows a course that is overlaid on an unaltered natural surface, but the course itself as a boundary of permissible running is artificial. And while one might row or paddle on a buoyed course, one might also do so on a river or ocean. 
alone. Remote sport takes what is there as its playing field and examines the human and the natural together. Urban sport is, in effect, a privately human conversation: it tests how well the participant measures up against a cultural ideal of the human. Remote sport is certainly still human, with human cultural ideals at work, but it adds something else: a revelation not only of the human, but of the world within which the human drama takes place. With this in mind, then, we can also say that while urban sport is fundamentally and thoroughly social in character, remote sport, while social in its origins, seeks to move outside the bounds of strictly social existence. Its performance is often profoundly social as well (the small groups that paddle, climb, ski, hike, etc., may be dependent on each other to an extraordinary degree), but the focus is on activity that is addressed at a deep level to the world that cares nothing for human society. And for many remote sportspersons the solitude and sheer quiet of the natural world apart is the compelling draw of their sport.

\section{Attitudes to Sport: Process vs Competition}

The rationalised core of modern urban sport may be a motivation behind the development of alternative or extreme sports. But much as some might like to see such sports as the antithesis of traditional competition-oriented sport, this is too generous an assessment of their character. Just because a sport is not played in an arena or against a time clock, or has no formal governing structure, that does not mean it is not competitive. Many of the proponents of recently developed "alternative" or "extreme" sports cite their disenchantment with mainstream competitive sport as the basis of their dedication to their own. Many mountaineers, as well, testify to this "noncompetitive" quality of their activities. For example, Joe Simpson states that mountaineering is "far, far more than sport. It is not done to win a game, to gain a gold medal, to beat a fellow competitor" (6: Introduction). Thus, one might conclude that alternative/extreme sports, which include a great many of the sports I have designated as remote (mountain biking, white water sports, rock climbing, extreme skiing and snowboarding, etc.), are process oriented, that is, about the experience itself and the development of sport-specific skill rather than the result or defeating someone else. If so, that would give us a plausible answer to our question: the gain of remote sport is this heightened experience of self and environment in interaction, a process of revelation of self and other, where the other is the natural world rather than a human opponent. Thus remote sport incorporates the same process of self-development and self-revelation as does traditional competitive sport, but its "opponent" and "partner" in this dialectical process is not another human but the natural environment. ${ }^{6}$

While this is a plausible initial characterisation of a possible outcome of remote sport, it would be an exaggeration to claim either that an inherent trait of alternative/extreme sports is this anti-competitive character or that its participants are necessarily eng aged in such a process. In truth, the opposition appears rather to be between individualist self-determination and the perceived suffocation of this individual spirit within a highly structured and controlling sport organisation. Alternative sport athletes don't want to be told what to do, but they remain highly competitive, both inwardly with themselves, and within their sports. The evidence argues that, just as with any other set of athletes, each is attempting to better their own

${ }^{6}$ Krein argues this way; see (11: p. 91). 
performances and to top others'. ${ }^{\text {? }}$

Those who participate in such sports frequently claim that they are not sports, so much as lifestyles. ${ }^{8}$ All sports, however, including conventional ones, have this aspect. There are those who participate casually and those who are utterly devoted. Any sport can be a lifestyle sport in this sense. Indeed, any sport that demands a high degree of fitness or training will enforce a lifestyle on its participants. The desire for this alternativity might be what motivates participation in some cases, but if this is true, it suggests that the participants take up their respective sports for reasons quite extrinsic to them as sports, in the sense of a set of physical skills and the experience of embodied movement entailed by the exercise of those skills, and in that case we are no better off in understanding the value of these sports as such.

The apparent rejection of the mainstream sport paradigm by those engaged in "alternative" sports, whether prefaced by the disavowal of competition or the avowal of lifestyle commitment, is somewhat overstated. More importantly for the present discussion, however, many of these sports also remain conventional in the prevalence of a use-orientation toward the natural environment. We can see this most clearly in those sports the primary purpose of which is to generate a thrill for the participant. The natural environment in such cases provides opportunities for thrill experience, but its existence in its own right is thus rendered essentially secondary. The development of skill, a prime goal of mainstream sport, is also secondary to the thrill seeking that such skill enables. Given these circumstances, there is no obvious reason why an artificial, urban, park wouldn't do as well.

Another critique of mainstream competitive sport and use-oriented attitudes to nature comes from a deep ecological perspective. Nils Faarlund, for example, decries the elitist, exclusivist results of goal-directed competition as destructive-an activity that generates "losers" cannot be expected to produce an harmonious self or society. ${ }^{9}$ Arne Naess elaborates on Faarlund's critique to lay out necessary elements of a sound friluftsliv, which includes discouraging goal-oriented outdoor experience in favour of an experientially-grounded identification. The important element for us here is the rejection of outdoor activity that is goaldirected in the sense of attempting to accomplish a pre-determined human project-getting to the summit, finishing a trail, getting those photographs, etc., in favour of an experience of nature that allows it to be experienced for its own sake. In Faarlund's case, the claim is also that a competitive approach to outdoor activity bespeaks an extrinsic rather than intrinsic (autotelic) motivation.

As Sigmund Loland rightly points out, there is a rather simplistic understanding of competitive sport at work here. Rather, he suggests, "if practiced within a sound framework, sport can be of significant ecological value" (13: 70). In fact, as he argues, "the good sport competition is built on an experience of a deep interdependency between persons in which all

${ }^{7}$ See almost any of the essays in Wheaton (26) or Rinehart and Sydnor (25). The element of competition among mountaineers is amply attested. See, for example, Messner (15: p. 86), where he admits that he wanted to solo Everest before Naomi Uemura: "I want to be the first who has climbed the highest mountain in the world alone."

${ }^{8}$ Belinda Wheaton (26: 4); as well as Simpson, in (6: Introduction).

${ }^{9}$ Quoted in Naess (16: 178-9). 
are enriched, or in symbiosis..." (13: 81). Yes, competitive sports can be destructive, but they can, and ideally should be, ones that enable all participants to engage in a process of selfdevelopment and self-realisation, through their dynamic interaction. As Loland puts it, From an ecosophical point of view, "winning" refers not to an end result, but to a process, to the quest for joy in competitive interaction with others, to the process of "playing to win". "Playing to win" represents an attitude concerned with the values of activities in themselves. Play is the paradigmatic example of activities with autotelic value. An understanding of sport as play rejects the idea of absolute, linear, and universal progress and focuses on the temporal and particular ideal of performance. The value of competition lies within the playful struggle for comparative superiority between participants....Sport is a cultural practice open to a variety of interpretations. Within a common, unifying framework created by a shared interpretation of the rules, sport offers the possibility of exploring an infinite number of relations with others. In competitive games we can experience in a very fundamental way sameness and otherness with other persons, which again is a strong expression of the unity and diversity of life. (13: 82)

At the same time, Loland also acknowledges some of the difficulties in incorporating competitive sport into an ecosophical perspective, in particular the problems of increased demand on resources and the instrumental attitude to the environment that is so often prevalent: how do we balance or overcome the tendency to look at a slope or a river as something distinct from us and on which we act, with a view that places us within those environments as one component of a dynamical whole, each element of which is involved in the flourishing of the whole? $(13: 70,85)$

Whatever the answer to these questions might be, the ecosophical attitude to sport would certainly counsel us to look more to the process of interacting with the natural world than to using it for selfishly human or individual ends; it would have us think of our remote sport encounters as opportunities to more fully and profoundly grasp our place in the ecological network that enables us to pursue such sports in the first place. It does not require that we attempt to preserve every minute component of it unharmed. ${ }^{10}$

North Americans tend to think of remoteness in the sense relevant to the present discussion in terms of pristine "wilderness", "untouched", i.e., unaltered by human, or simply white European, civilisation. There are at least two major problems with such a conception. As William Cronon has persuasively argued, "wilderness" is a cultural construction, one that is based on a distinctly dualist understanding, and that incorporates centuries of mythical and philosophical projection of human hope and fear onto the natural world as distinctly other. ${ }^{11}$ Another reason to avoid the concept is that, arguably, wilderness doesn't really exist, not only because it is a human projection, but because there are very few, if any, extensive areas of the

\footnotetext{
${ }^{10}$ See Naess' comments in “Intuition, Intrinsic Value, and Deep Ecology”, in Witoszak and Brennan (17: 169).

${ }^{11}$ William Cronon (3). See also Nelson (18: 367-370), and Macfarlane (14), who cover similar ground with respect to European attitudes to the high mountains.
} 
world that have not been altered or affected in some way by human activity. ${ }^{12}$

What is critical here is an ecologically-grounded viewpoint, one that places central importance on the value and integrity of the environment or its natural constituents in their own right, and that enjoins us to find human value within that context rather than in opposition to it. There are a number of theoretical approaches that fit this bill and many avoid the metaphysical and ethical difficulties adhering to Deep Ecology per se. Thus, I do not think that we need commit ourselves to that specific theory, rather than some alternate ecologicalphilosophical approach, in order to agree that stressing the elements of process, integration with the natural world, and self (if not Self) realisation as properly normative in those activities that I have designated remote sport brings us quite a bit closer to explaining the benefit of remote sport. It is better to climb a remote cliff face because doing so allows for greater selfrealisation through immediate interaction with the environment.

The preceding considerations will, in the end, I think, prove decisive in the attempt to offer a coherent philosophical justification for remote sport activities. However, one very large area of concern in connection with such sports is the degree of risk with which they seem to be associated. Does such risk either validate or invalidate remote sport, supposing that it is truly risky? I turn to such questions in the next section.

\section{Risk}

Many remote sports are certainly risky. But are these risks either quantitatively or qualitatively distinct from those in urban sport? One can drown in the Nahanni, far from any rescue, and one can drown in the South Saskatchewan in the middle of the city of Saskatoon. Drowned is drowned, one might say, what difference does it make where, or whether it is the result of trying to shoot the rapids in an open canoe or smacking into a bridge while wakeboarding? There are extremely risky urban sports-Formula One racing, for example. Given that there is a higher than average risk of death or hideous injury, we cannot say that the gain of remote sport over urban is simply the presence of risk. Remoteness, however, elevates risk insofar as it makes it much more difficult and often impossible to provide aid in either a timely fashion or at all. To be injured in the backcountry may well, under certain circumstances, presage a slow, lonely, lingering death. One might for this reason argue that the remote sportsperson's assumption of risk is more meaningful and their dedication to the sport more decisive, as indeed Dougherty seems to suggest in asserting that the real risk of injury imparts authenticity to the climbing experience. Bolt-protected climbing is a less authentic mode of

\footnotetext{
${ }^{12}$ Granted, although wilderness only exists in the minds of human beings, it seems that we can still make plausible distinctions between, e.g., ancient short-grass prairie and a botanical garden, and since we are humans and we think, we will inevitably impose human ways of thinking onto the world. Moreover, although wilderness may indeed be a false concept in the sense that no such place exists except in the human imagination, that does not in any way rule out the actual, even if mistaken, search for wilderness either as a motivation for certain kinds of sport activity nor as an interpretive framework for evaluating experience and ontological gain. Nor does it rule out the possibility that there may be good human and environmental reasons for doing what we can to ensure the survival of relatively "wild" areas. It is because of considerations such as these that Dougherty adopts the expression "wilder place" instead of "wilderness" (5: 94-6), in which usage I concur.
} 
engagement, he says, because "[o]ne of the key elements of a full climbing experience is missing to a great extent-namely the uncertainty of a successful and safe outcome." By contrast, leaderplaced protection "ensures some doubt as to the outcome" and is "an enhanced kinaesthetic experience", requiring as it does the control of fear and a more complex physical and technical task (5: 100).

The goal of the mountaineer is, nevertheless, to accomplish a difficult route successfully and not die. If all one wanted was risk, one could do much less elaborate and expensive things than climb mountains. One could play dangerous sports at which one was incompetent, or drive one's car at high speed blindfolded. Risk alone cannot be the overriding motivation, much less a justification, for doing these sports. Granted, the awareness of the possibility of utter and irrecoverable disaster has to be present for the mountaineer as it is unlikely to be for the conventional game player. And that awareness of the proximity to total destruction may well be, as Simpson and others suggest, an element in the attraction to dangerous sport-the enormous cost of not getting the next move right-that would not be available in the great majority of urban sports. ${ }^{13}$ But, in fact, it is just this realistic appreciation of risk that makes such sports as safe as they are: paddlers wear pfd's and helmets and carry whistles and rescue gear as a matter of course, and mountaineers and rock-climbers, in whatever discipline they climb, pay the utmost attention to their protection before setting out.

As important a role as risk might play, it has to be a secondary one. The point of the sport is to successfully ski the slope, paddle the river, reach the summit, or at least develop one's skills at these activities, to have a good time with friends, to see and experience the awfulness or beauty of the environment, whichever it may be-and then go home again relatively unharmed. Risk adds to the experience in some way, but it is not the goal. One does activities that are risky despite the risk because they are more difficult to do and thus success at those activities is more satisfying.

However, risky activities can be difficult for two quite distinct though commonly coincident reasons. 1) Such activities are frequently more technically difficult, and thus the requirement of greater skill, endurance, preparation, and ingenuity may be what offers the participant a special appeal. 2) Distinct from this, though perhaps not separable in actuality, is the psychological effect on the participant of the awareness of risk, i.e., fear. Fear can make an activity more difficult to perform, but its presence can also make successful performance more satisfying. One reason for this is already suggested by what has just been said-fear often makes otherwise familiar actions more difficult. But it is also the case that fear can take on a pseudoexistence for someone attempting to do something that they find frightening. In such a case, fear becomes something that must be conquered in order for the person to do what they want. And thus we talk about overcoming one's fears as a goal in performing certain kinds of risky activities. But apart from the explicitly thrill-oriented "sports", there is something of a conceptual confusion here. The goal in risky sport is to accomplish some other activity despite

${ }^{13}$ Joe Simpson, in (6). Compare as well these comments from Jim Curran, quoted by Jon Krakauer (10: 162): "I think if you're going to try alpine-style ascents of 8,000 metre peaks you've got to leave yourself room to fail." And, Willi Unsoeld's remark, "It has to be real enough to kill you," (quoted by Watters (25: 258). 
one's fears or, alternatively, using one's fear as a goad to push one farther. ${ }^{14}$ Otherwise, indulgence in thrill sports would, indeed, be enough. But note a crucial point here; whatever value is gained in performing an activity despite one's fear is lost if one succeeds in eliminating the fear altogether. ${ }^{15}$

Simpson and Messner both seem to suggest that fear functions as a personal challenge: it is in the situation of high risk, in which an intelligent person experiences a profound and reasonable fear, that one can also experience a greater than normal awareness of one's existence, abilities, and limitations. Neither risk nor fear are ends in this picture, but means-means to an intensified experience of oneself in one's situation, and of one's ability to cope with the situation skilfully and successfully. What risk adds to the remote sport experience, it could then be argued, is the opportunity for a heightened testing of one's ability and character, and ultimately an affirmation of one's self.

While such athletes do not seek out risk per se but devote a considerable portion of their preparation and expense to eliminating avoidable risks, it is also the case that these sports are themselves avoidable risks. No one needs to do such sports-that is what makes them sports. But the specific skills of each such sport are what navigate the sometimes narrow passage between tedium and disaster. As Kevin Krein comments, "the goal of adventure athletes is not to leave survival up to chance, or to gamble with one's life, but instead...they seek situations in which they have control and responsibility for their lives and in which survival depends on their judgement and skills" (11:87). He adds that such athletes do not go looking for situations in which death is a likely consequence. Rather, "[w]hen there are close calls, they are the result of uncontrollable hazards, or mistakes that result from an athlete choosing an objective that is not within his or her ability, or from carelessness on the part of the athlete." Such athletes are, like any others, looking for situations in which they can exercise and further develop their skills, "so that they can take on more difficult challenges" (11: 87).

A recurrent theme in this connection is that of testing oneself. We are used to the idea of sport as a contest, but this generally presupposes that the athlete is engaged in a struggle with another human being. While this is sometimes the case in remote sport, as when one wants to get up the mountain or down the slope ahead of the next person, such direct competition is, more often than not, absent. Indirect competition is frequently present: one wants to accomplish some route faster, with less equipment, or to be first in some ever vanishingly defined category (i.e., first Canadian asthmatic female rower carrying three cats, and so on). Sometimes one talks of competing against no one but oneself. Krein thinks such language makes little sense in this context: competition requires two active competitors and whereas a track athlete can attempt to improve her personal best time, remote sport doesn't take place in

\footnotetext{
${ }^{14}$ "My worst enemy on the way to this goal is fear. I am a timid person, and like all timid people I long to overcome my fears. Victory over fear, that is also a happiness in which I am close to myself....I want to have the feeling of being stronger than my fear, that is why again and again I place myself in situations in which I meet it in order to overcome it." Messner (15: 87.

${ }^{15}$ This may help to explain why one becomes "addicted" to danger: as one becomes more adjusted to one level of risk, one must seek a higher level to feel the same degree of accomplishment. Routes, etc. become "too easy".
} 
such regular conditions and so such measures of success are inapplicable (11: 89). ${ }^{16}$

More can be made of this sense of self-competition than Krein allows, however. If any sense can be made of the notion of remote sportspersons improving their skills, as Krein does admit, then it seems that one can compete against oneself in this respect, but more telling is the circumstance that any athlete will at some point experience the need to push herself to continue when she would very much like to stop. The testing that the athlete experiences, including one in a remote environment, is very often the struggle simply to continue and not quit. In such situations, one may talk to oneself, thus replicating in a way the adversarial quality of conventional sport, but it remains no less an inherently individual struggle, a test at which one can succeed or fail, and the most significant of tests for any athlete, in any kind of sport. It so happens that in remote sport, failure in the test can sometimes be final.

Robert Macfarlane, in tracing the history of the European fascination with high mountains, observes that the "idea of risk-taking as a test...dominates nineteenth-century attitudes towards fear. The deeper one advances into the century, the more entangled become concepts of risk with concepts of selfhood and self-knowledge." (14: 85) J. S. Russell's discussion of dangerous sport, it seems to me, fits into this tradition.

"Dangerous sport," Russell remarks, "can incorporate a challenge to capacities for judgement and choice that involves all of ourselves-our body, will, emotions, and ingenuity-under conditions of physical duress and danger at the limits of our being" (Russell (19: 14). Thus, he argues, such sport offers the opportunity for self-affirmation in situations where all our distinctively human being is challenged. The greater the obstacles we face in these situations the greater the achievement. "And so in confronting serious physical danger through our own choice and actions, we can be affirming our being by meeting and extending the boundaries of our existence. In this sense, dangerous sport can often appear to challenge us to the very limits of what it is to be a certain type of embodied rational being" (19: 14).

If this analysis is correct, it gives us a definite answer to the question of what there is to gain from remote sport, insofar as remote sport is also dangerous sport, and these two terms are not synonymous. Once again, if urban sport is dangerous, then it ought also to have the ontological benefits that Russell stipulates. This, then, while it gives us an account of what might be gained in remote sport, is not complete, as not all remote sport is dangerous in Russell's sense. ${ }^{17}$

Russell's discussion of dangerous sport concludes that its value is primarily in its affordance of a self-affirmation that cannot be attained in ordinary life. As he also puts it,

${ }^{16}$ There are quite a few mainstream sports of which this is true as well: rowing, in which weather conditions are variable and uncontrollable, and most games which, despite the enthusiastic compiling of statistics, are dynamic and thus internally variable.

${ }^{17}$ Russell's definition is: "a sport that involves activity that itself creates a significant risk of loss of, or serious impairment to, some basic capacity for human functioning." This significant risk is or should be "an expected outcome from time to time that is directly attributable to the specific activities involved in the sport itself and that exceeds the risk of such injury found in the participant's day-to-day life outside of sport by more than a modest degree." (Russell, 3) Russell also distinguishes dangerous sports from dangerous amusements (bungeejumping and other thrill-oriented activities) (19: 5). 
Dangerous sport in its best exemplars, particularly those in which substantial bodily danger is an immediate and ever-present risk, represents an opportunity for confronting and pressing beyond certain apparent limits of personal, and indeed human, physical and psychological capacities in ways not afforded by other normally available human activity. Thus, I say that the dominant, distinctive value of dangerous sport consists of an activity of self-affirmation because dangerous sport invites us to confront and push back the boundaries of the self by creating contexts in which some of the ordinary bounds of our lives can be challenged. Hence, we discover and affirm who we are and what we can be by confronting and attempting to extend these boundaries. (19:2)

All this seems right and good, but there is cause for caution here as well. First of all, Russell's language is cast in terms of seeking out danger in order to push back one's boundaries, thereby affirming one's self. Putting matters this way gives weight to Russell's reference to romantic militarism; the picture presented is one of an otherwise highly, perhaps overly, civilised human being, who experiences the need to prove himself more than a mere civil unit. ${ }^{18}$ By making one's mark upon the world, particularly in dangerous or remarkable ways, one affirms one's existence, and denies one's transience and insignificance.

But this is not the kind of self-affirmation Russell has in mind and because of this we need to be careful about what we mean when we talk about the "self-affirmation" afforded by dangerous sport. "Self-affirmation" is sought in many ways, some positive and some self- or other-destructive, and it may be entirely social, as when one seeks the recognition of the public, one's peers, or superiors, or it may be of the profoundly inward and existential sort, as when like Sisyphus with his rock one applies oneself to a task that concerns a self-worth of which no one else will ever know. And still, these actions may not lead to the self-awareness to which Russell points. In the best of cases, however, both remote and dangerous sport can, though by no means must, generate such moments of self-affirmation and self-revelation. But, while it can reasonably be argued that self-knowledge properly requires society of some sort to be attained, the practice is inherently self-reflective rather than externally reactive. The last quotation from Russell (19: 2) can be read this way, i.e., as making the case for self-knowledge as a product of a reflective engagement in dangerous sport. But in the case of remote sport in particular (whether dangerous or not) there are also enhanced possibilities for a particular kind of self-knowledge, that is, of one's self-in-nature. That is, in remote sport one encounters one's own limits and abilities in the engagement with obstacles which stand outside one as measures of one's existence, and over which one's influence is at best problematic. Moreover, one's interaction with this environment is telling not only of one's social or personal self but of one's connection with the natural world, one's significance (or lack thereof) as an ecologically implicated organic being, one that can reflect on that connection and learn and determine what it means for oneself.

Self-knowledge, however, is also a complicated goal. Like happiness, it tends to come along as a byproduct of other activity rather than something that can be directly aimed at.

\footnotetext{
${ }^{18}$ This view seems to be supported by Messner's characterisation of his own motivations in The Crystal Horizon (15) (see, e.g., p. 87), but it is denied by Heinrich Harrer in The White Spider, his account of the first successful ascent of the North Face of the Eiger, in which he participated in 1938 (6); see page 114.
} 
Unlike happiness, it can be directly sought and, one hopes, attained by deliberate effort. But one of the values of sport is precisely that it can be a reasonably effective secondary route to selfknowledge. It is also reasonable to contend that remote sport in particular, in part due to the element of risk, is in many cases better suited to the pursuit of this goal than conventional sport, and many no doubt take up remote sports for exactly this reason. There are a number of reasons for this. First, many people pursue remote sport, including its less risky varieties, in order to get away from the busyness and chattering concerns of urban life, to be able to think and reflect clearly. Second, urban sport, with its emphasis on direct competition in many of its iterations, may be seen as merely adding yet another distraction to the reflective process. Third, the need for self-reliance in remote sport makes a somewhat heightened demand on the individual to understand his or her capacities and limits, but fourthly, the element of risk ups the stakes in an important way. The participant must eventually confront the question of what are his or her priorities in life really. And while many urban sports are also risky, in common with other urban sports they can be walked away from in the moment of doubt, whereas remote sport is frequently all-committing. The differences here are less of kind than of severity.

Although I cannot explore this here, we ought also to question the value that remote sportspersons place on risk, both personally and socially, and not simply accept its putative worth for individual self-affirmation or self-knowledge without reservation. Macfarlane puts the point quite succinctly. He says:

There are many ways to die in the mountains: there is death by freezing, death by falling, death by avalanche, death by starvation, death by exhaustion, death by rockfall, death by ice-fall and death by the invisible aggression of altitude sickness, which can cause cerebral or pulmonary oedema. Falling is, of course, the ever-present option. (14: 97)

He then offers the following remark: "People who regularly take big risks in the mountains must be considered either profoundly selfish, or incapable of sympathy for those who love them" (14: 98). The acceptance of risk in such sports is frequently treated as a matter of strictly personal choice, but there are at least two problems with this: given that few humans are indeed atomistically isolated free agents, such choices are not strictly personal, but more often than not affect the lives of others and, as Ruth Seifert puts it, the acceptance of risk by (in this case) mountaineers is unreal because their sense of risk to themselves is entirely abstract-they don't think that disaster will really happen to them; terrible things happen to other people, not them, because they are careful. ${ }^{19}$

These objections aside, one can make the case that what risk offers to the performance of sport, remote or urban, is a heightening of experience; more specifically, risk constrains the situation in such a way as to demand that the participant concentrate her physical and mental skills to such a degree and in such a way as to block out consideration of anything but the activity engaged in. Risk, in effect, enforces peak performance and heightened experiences of the phenomenological state of flow. ${ }^{20}$ The participant must silence extraneous thoughts and put herself entirely in the present moment or else there will be no future moments. If such

\footnotetext{
${ }^{19}$ Quoted in Coffey (2: 138).

${ }^{20}$ See Coffey (2: 22-24).
} 
experiences qualify as intrinsic goods, then incurring risk would seem a justifiable cost. However, such good is individual and achieved at the cost of risk not only to the agent, but possibly to others connected with the agent, and possibly also the environment in which the agent acts. These latter costs may also need to be weighed. Russell is right to claim that a benefit of risk sport is self-knowledge (15), and I take self-knowledge to be a primary good. But it is also true that it may not be had under these circumstances without costs beyond those to the agent alone.

\section{Finding Oneself in Wild Places}

Most sport struggle is entirely social-its rewards, costs, and performance are socially defined and exist only in the social. The athlete who triumphs or fails in the big contest is made "immortal" or a byword for shame only in social existence. What is at stake on a high altitude peak or in a raging torrent is, in some respects, different. It is not lacking in social aspects; it is not uncompetitive. One can engage in remote sport in a way that maximises the social: it becomes about reputation, or spending time with your friends. Or one can engage in a way that emphasises one's relationship with the environment itself.

One might hope that those who participate in remote outdoor sport do so out of some sort of respect or love for the natural environment. This need not be so. Much outdoor or remote sport is profoundly use-oriented: the hills, the slopes, etc., may be great places to ski or to mountain bike because the severity or unpredictability of the terrain makes for a good ride. Likewise, having oneself helicoptered out to a remote summit so that one can ski deep fresh powder does not necessarily indicate a reverence for the natural world in its own right. And the number of snowboarders who get lost going off trail in the backcountry, requiring rescue, suggests that love of the world outdoors does not necessarily extend to a willingness to make oneself aware of its hazards. Remote sport need not be noble or enlightened; it can be entirely exploitative and people may come out of their encounters with the environment as ignorant of themselves and of wild nature as they went in. One can engage in remote sport and still be fixated on "conquering the wilderness" or some similar stance; spending time in wild spaces is not an automatic cure for bad attitudes toward the earth. Or the sport activity may be part of a process of considerably deeper engagement and the natural environment may be an essential element in a process of discovery. This may too have a strong use-orientation or it may be an educational and revelatory experience of embodied nature.

The set of assumptions and interpretational frameworks that we bring to a situation will have its say in how we experience it, what actions we choose to take, and, of course, which of these basic attitudes is likely to inform our environmental interaction. We cannot approach nature without carrying with us a very large background of social interpretation. As Robert Macfarlane puts it,

We don't come fresh to even the most inaccessible of landscapes....We carry expectations within us and to an extent we make what we meet conform to those expectations...A raft of largely undetectable assumptions and preconceptions affects the way we perceive and behave in a place. Our cultural baggage-our memory-is weightless, but impossible to leave behind. (14: 195)

Whether the remote sportsperson's narrative of events is one that centres on her relationship to the feature of the natural landscape with which she engages, and whether that is a "shallow" or "deep" one, or whether she fails to see any such relationship, is strongly dependent on both 
prereflective and consciously chosen perspectives. There are several ways in which one can approach and interact with wild places. One can treat them as attractive and convenient backgrounds for anthropocentric leisure pursuits. This would include urban sports that merely happen to be pursued out of doors. Such sports offer to their participants what all sports do: the opportunity to develop personal and interpersonal skills, including a deepened awareness of oneself as a reflective being. Unfortunately, such sports may not contribute to a particularly deep understanding of the environment in which they take place, and they may contribute to its continued degradation.

One might, instead, pursue sports that take the environment or some feature of it as the central determining and independent element to which human activity is directed. One might do so with any number of motivations. For example, a need to "conquer the wilderness", to experience the sublime in the awesome beauty and power of nature, or because one seeks to engage in a dialogic immersion of self in environment, to name a few. However, while all of these possibilities may have their various benefits for the participant, just as urban and useoriented outdoor sports do, there is an important difference between them, one that is critical for achieving the unique benefit of remote sport to the participant who approaches it in a particular way, i.e., an enhanced knowledge of both self and self-in-nature.

I shall concentrate on the last of these since it is a reasonable fair characterisation of an ecosophical approach, which I referred to in the earlier part of this paper, and because it helps to present the problem most clearly. The fit of ecosophy or deep ecology with sport, including remote sport, is problematical. From the ecosophical point of view, more ecological awareness leads one to greater Self-realisation, and thus one might argue that sport that took one into situations where one could have the appropriate ecological encounters would also enrich the self by advancing one's Self-realisation. Thus, in defending competitive sport, Loland argues that the exploration of the diversity and complexity of embodiment (13: 79), and of the relational body (13: 80), that sport provides can be extended into a similar exploration of one's continuity with the environment, thus "[i]f practiced in closeness to nature, sport possesses a strong potential for developing sensitivity for the environment" (13: 84). This is quite true. But notice that we choose to engage in remote sports, whether out of a desire to prove ourselves in the "wilderness", to experience the sublime in nature, or out of a desire to achieve something like an ecosophical Self-realisation, because we think that such things are good, because they fit human values, and to do these things we need to be able to engage in a process of self-definition that is also a self-affirmation of ourselves as distinct from our environment, whether that is natural or artificial. Mountain-climbing and Deep Ecology are equally human projects, and if we weren't able to see ourselves as human and need to understand our humanness, we wouldn't engage in either. Put bluntly, self-knowledge involves awareness of the extent to which we are our own distinct selves in the sense of responsible agents, responsible for ourselves and our interactions with the natural world and its wilder parts. And that means that treating the wilder world as we ought entails recognising that we are not identical to or dissolved in it; we are reflective moral agents who have to figure out what is the right thing to do. In this way, respect for the natural world is very like respect for other human beings: we can't treat either of them as if they were indistinguishable appendages of ourselves.

Where does this leave us in the attempt to find an explanation of the ontological value of remote sport? I think the answer is a hybrid one. Risk alone cannot explain the value of remote sport, but it does play a significant role. Whether the risk incurred is of swift death or distance from rescue or companionship, risk's contribution seems to be its heightening of the imperative 
that operates in all sport to concentrate on the moment, to effect the crucial connection between awareness and embodiment. Risk sharpens the attention to detail and to one's priorities and values. This in itself can be a state of mind that the remote sportsperson seeks out: the absolute need for clarity of purpose and performance, and the heightened awareness of self and environment, especially to the point of silencing mental chatter and ordinary preoccupation with social busyness. In these respects, one could say that one loses (silences) one's civic self, not necessarily in order to but with the consequence that, one clarifies one's personal self. One then gains knowledge of self both in one's limits and in one's connections. ${ }^{21}$ Risk contributes to the clarification of who we are, what we value, and what we are willing to do about it. It is a valuable element in developing a knowledge of one's self. It also, in the remote sport context, is a powerful incentive to make sure one understands as fully as possible the environment in which one intends to act. If one's life depends on understanding cloud formation and river hydraulics, one is rather more likely to acquire the relevant information-which will itself enrich one's experience. At the same time, the broadly ecosophical viewpoint offers an interpretative framework for understanding both the embodied and ecologically-situated nature of human existence, especially in a way that puts the natural environment at the centre of the sport experience. Ecosophical knowledge is, after all, knowledge not only of the world outside of us, but of how we are part of that world, of our nature as ecologically-situated beings, just as undertaking risk in remote environments can also remind us of our fragility and dependence on other humans and environmental conditions. More simply, remote sport reminds us of who we are in the wider scheme of the earth; it cuts us down to size and shows us the reality and beauty of the planet we take for granted. Risk combines with the ecosophical viewpoint in insisting on the importance for our own survival of learning about self, nature, and self-in-nature; it sharpens one's resolve. Do we need risk to have such an experience? Ultimately, I think not. In the end, it may be that neither risk nor simple geographical distance are necessary for acquiring awareness of the symbiotic humannature interrelationship, but they can help to cut through the accretion of social noise and mental clutter to get to it. $^{22}$

\footnotetext{
${ }^{21}$ “'At least as important as success is joy at one's own skill. It is astonishing how often I have overlooked this part of the pleasure of climbing and have talked solely of loads carried to the summit. High altitude climbing requires a whole range of proficiencies, knowledge and inventiveness. The higher you go, the more man himself becomes the problem. Ability also to solve problems of this sort is what makes a good climber. I see the usefulness of climbing not in the further development of technique, rather in the development of the instinct and proficiency of man to extend himself. Learning about his limitations is just as important as his claim to be able to do anything." Messner (15: 231).

${ }^{22}$ This paper owes a great deal to the many who have heard, read, and reviewed it in its various incarnations. My thanks to all for their comments, which have been invaluable in refining my thoughts on these subjects.
} 
Remote Sport 16

\section{Bibliography}

1. Bell, Martha. “'Another Kind of Life': Adventure Racing and Epic Expeditions”. In Rinehart, Robert E. and Synthia Sydnor (Eds). To the Extreme: Alternative Sports, Inside and Out. New York: SUNY Press, 2003: 219-253.

2. Coffey, Maria. Where the Mountain Casts its Shadow: The Dark Side of Extreme Adventure. New York: St. Martin's Press, 2003.

3. Cronon, William. "The Trouble With Wilderness; or, Getting Back to the Wrong Nature". In Cronon, William (Ed.) Uncommon Ground: Toward Reinventing Nature. New York: W. W. Norton \& Company, 1995: 69-90.

4. Dahle, Børge. "Friluftsliv: Life-long learning-Experiences-Reflection-Acknowledgement". http://www.mesa.edu.au/aaee_conf/Dahle-Borge.PDF.

5. Dougherty, Alan P. "Aesthetic and Ethical Issues Concerning Sport in Wilder Places." In McNamee, Mike (Ed.) Philosophy, Risk, and Adventure Sports. London: Routledge, 2007: 94-105.

6. Harrer, Heinrich. The White Spider. London: Harper Perennial, 2005.

7. Henderson, Bob. "Friluftsliv". Trumpeter 14, 2 (1997).

http://trumpeter.athabascau.ca/content/v14.2/henderson2.html

8. Krakauer, Jon. Into the Wild. New York: Anchor Books, 1996.

9.___ Eiger Dreams: Ventures Among Men and Mountains. New York: Anchor Books, 1997.

10. . Into Thin Air. New York: Anchor Books, 1997.

11. Krein, Kevin. "Nature and Risk in Adventure Sports". In McNamee, Mike (Ed.) Philosophy, Risk, and Adventure Sports. London: Routledge, 2007: 80-93.

12. Lewis, Neil. "Sustainable Adventure: Embodied Experiences and Ecological Practices Within British Climbing”. In Wheaton, Belinda. Understanding Lifestyle Sports: Consumption, Identity, and Difference. London: Routledge, 2004: 70-93.

13. Loland, Sigmund. "Outline of an Ecosophy of Sport". Journal of the Philosophy of Sport XXIII (1996): 70-90.

14. Macfarlane, Robert. Mountains of the Mind. London: Granta Books, 2003.

15. Messner, Reinhold. The Crystal Horizon. London: The Crowood Press, 1989. 
16. Naess, Arne. Ecology, Community, and Lifestyle. Translated and Edited by David Rothenberg. Cambridge: Cambridge University Press, 1989.

17. . "Intuition, Intrinsic Value, and Deep Ecology". In Nina Witoszak and Andrew Brennan (Eds.), Philosophical Dialogues: Arne Naess and the Progress of Ecophilosophy. New York: Rowman and Littlefield Publishers, Inc., 1999: 166-170.

18. Nelson, Michael P. "Rethinking Wilderness: The Need for a New Idea of Wilderness". In Joseph DesJardins (Ed.), Environmental Ethics: Concepts, Policy, Theory. Mayfield (1999): 366-370.

19. Russell, J.S. “The Value of Dangerous Sport”. Journal of the Philosophy of Sport XXXII, 1 (2005): $1-19$.

20. Sandell, Klas. "Outdoor Recreation and the Nordic Tradition of 'Friluftsliv': A Source of Inspiration for a Sustainable Society?" Trumpeter 10, 1 (1993).

http://trumpeter.athabascau.ca/content/v10.1/Sandell.html

21. Simon, Jonathan. "Risking Rescue: High Altitude Rescue as Moral Risk and Moral Opportunity." In Ericson, Richard V. and Aaron Doyle. Toronto: University of Toronto Press, 2003: 375-406.

22. Simpson, Joe. The Beckoning Silence. London: Vintage, 2003.

23. . Touching the Void. London: Vintage, 1997.

24. Todhunter, Andrew. Dangerous Games: Ice Climbing, Storm Kayaking, and Other Adventures from the Extreme Edge of Sports. New York: Doubleday, 2000.

25. Watters, Ron. "The Wrong Side of the Thin Edge". In Rinehart, Robert E. and Synthia Sydnor (Eds). To the Extreme: Alternative Sports, Inside and Out. New York: SUNY Press, 2003: 257-266.

26. Wheaton, Belinda. Understanding Lifestyle Sports: Consumption, Identity, and Difference. London: Routledge, 2004. 